NBER WORKING PAPER SERIES

SOCIAL SECURITY AND LABOR SUPPLY INCENTIVES

Roger H. Gordon

Working Paper No. $\underline{986}$

NATIONAL BUREAU OF ECONOMIC RESEARCH

1050 Massachusetts Avenue

Cambridge MA 02138

September 1982

The research reported here is part of the NBER's research program in Taxation. Any opinions expressed are those of the author and not those of the National Bureau of Economic Research. 


\section{Social Security and Labor Supply Incentives}

\section{ABSTRACT}

Many provisions of the Social Security Program distort an individual's labor supply incentives. In particular, the payroll tax, the earnings test, the offsetting actuarial adjustment, and the dependence of the size of future benefits on the level of current earnings all affect the net return to extra work. The purpose of this paper is to estimate the size of the net tax rate on labor income in a variety of circumstances, taking into account all these provisions, as well as the personal income tax. We find that the Social Security Program on net in the past has provided a large subsidy to labor supply, which for many people effectively offset the personal income tax. This subsidy rate, however, has been declining steadily over time. 


\section{SOCIAL SECURITY AND LABOR SUPPLY INCENTIVES Roger H. Gordon* \\ Bell Laboratories \\ Murray Hill, New Jersey 07974}

Many provisions of the Social Security Program distort an individual's labor supply incentives. In addition to the payroll tax, whose current rate is $13.4 \%$ (combined employee and employer rates), those qualified to receive Social Security benefits face the earnings test, which imposes a tax rate of $50 \%$ on earnings. To the extent that benefits are withheld, however, future benefits are increased through an actuarial adjustment (or, after age 65, a delayed retirement credit). Also, since the formula used in computing benefits depends on past earnings, the return to work increases whenever extra work leads to extra future benefits.

Not only are these explicit or implicit tax rates large, but they have been changing substantially across time. The 1977 Social Security amendments, in particular, had a large effect on these tax rates for most people. In addition, younger cohorts face very different effective tax rates than older cohorts, even at the same date.

Individuals, when deciding when and how much to work, must take each of these tax effects into account. Rather than basing their labor supply decisions solely on the market value of the output they produce, as economic theory argues would lead to efficient decisions, individuals must worry as well about how their taxes and Social Security benefits change when they work more. To the extent that they revise their labor supply decisions in response to these various taxes and subsidies, efficiency costs arise. Given the large size of many of these distortions, the resulting efficiency costs could be quite severe.

It is too easy, however, to focus on any one of these distortions in isolation, and argue that cutting the size of that distortion would lead to important efficiency gains. ${ }^{1}$ The size of the efficiency cost depends on the net distortion left when all the various effects of Social Security

- Bell Laboratories, Murray Hill, New Jersey. The views expressed in this paper are those of the author, and do not necessarily represent those of Bell Laboratories or the Bell System. 
are combined together with the personal income tax and any other labor supply distortions, such as may arise from private or state and local government pension plans. ${ }^{2}$ Calculating the size of this net distortion is quite complicated, but is necessary in order to judge the efficiency effect of any one particular distortion.

The purpose of this paper is to estimate the size of this net tax rate on labor income for various cohorts at various stages in their lives. ${ }^{3}$ Since many effects must be taken into account, each of which can vary greatly in size for different individuals, the reported numbers are intended to be merely illustrative rather than in any way definitive.

\section{Derivation of Net Tax Rate}

When an individual considers whether to work more and earn an extra dollar, to what degree do the taxes he pays, or the transfers he receives change as a result? The net change in the sum of these various taxes and transfers is the net tax rate on labor supply that he faces. In this section, we will describe what information we need to measure this net tax rate.

The largest extra tax an individual normally pays when he works more is the personal income tax. Denote his marginal tax bracket by $m$.

In addition, he must pay extra payroll taxes, as long as he is covered by Social Security, as we assume, and has not already in that year earned more than the maximum taxable earnings under Social Security $(\$ 29,700$ in 1981$)$. Let the statutory total payroll tax rate for all the combined Social Security programs be denoted by $p(6.65 \%$ in 1981$)$. Both the employee and the employer must pay this tax. Since the employer's contribution is implicitly deductible from taxable income under the personal income tax, the net payroll tax rate is $p(2-m)$.

The individual's extra dollar in earnings may also raise his future Social Security benefits. Any resulting increase in the present value of future benefits provides a subsidy to current labor supply. The calculation of the size of this subsidy is quite complicated, however. A description of the procedure prior to 1977 is found in Blinder, Gordon, and Wise (1980), while 
a description for the current law is found in the appendix. Let us denote the resulting increase in the present value of future benefits, if any, resulting from an extra dollar of earnings by $b$.

These three effects would normally occur for individuals of any age. For those who are already qualified to receive benefits, however, an additional tax may arise as a result of the earnings test. According to the current law, any individual between ages 65 and 69 , and any individual between 62 and 64 who has already registered for Social Security benefits, can have some or all of his Social Security benefits withheld to the degree that he earns more than an exempt amount. In particular, in 1981 , if an individual has already earned at least $\$ 5,500$ in that year, and then earns an extra dollar, his Social Security benefits in that year will be reduced by 50 cents (assuming he is still receiving any). Denote this tax rate, which is either .5 or .0 , by $e$.

To the degree that he does lose current benefits, however, his future benefits will be increased. For individuals aged 62 to 64 , the intent of the law is to provide an actuarially fair increase in future benefits for those who forego current benefits. For those 65 to 69 prior to 1977 the increase in future benefits was very small, but the 1977 amendments tripled the size of this delayed retirement credit to the point where it is now almost half the size of the adjustment for those aged 62 to 64 . Let us denote the average size of the present value of this compensating increase in future benefits by $a$.

Given the distortions described above, the net tax $t$ paid on an extra dollar of earnings equals

$$
t=m+p(2-m)+e-b-a
$$

In principle, we could add yet further distortions. State income taxes are omitted, as are distortions created by private pension plans. In addition, the individual may face sales taxes when he tries to spend his earnings. For simplicity, we ignore these further complications. 


\section{Measurement of the Net Tax Rate}

The main purpose of this paper is to calculate the size of this net tax rate $t$ for individuals in various cohorts at various stages in their lives. In particular, we calculate the net tax rate at four ages, $45,55,62$, and 65 , for individuals in each of three cohorts, those born in 1910 , 1920, and 1940. The calculations reflect the experiences of an average male worker with or without a wife receiving spouse's benefits under Social Security, and an average female receiving either worker's benefits or spouse's benefits.

The resulting numbers appear in Table 1. Details concerning the calculations of these numbers can be found in the appendix. A number of assumptions are made in calculating these numbers. For example, it is assumed that:

1) Individuals had perfect foresight concerning what benefit formula they would face at retirement. As a result, these numbers reflect the net tax rate ex post, and not necessarily that which individuals thought they faced at the time.

2) By 2005 , individuals are assumed to qualify for full Social Security benefits at age 68 rather than at age 65 , and for reduced benefits at age 65 rather than at age 62 . As a result, it is assumed that 38 years of earnings rather than 35 will be used in computing the size of Social Security benefits. In all other respects, the benefit formula is assumed to remain unchanged.

In addition, we have assumed that extra earnings at each of these ages will result in extra future Social Security benefits, and that after age 62 , the individual will have extra Social Security benefits withheld when he works more. In any given situation, though, either or both of these effects could equal zero, implying dramatic changes in the net tax rate $t .4$ In particular, as a result of the 1977 amendments which blow up earnings at earlier ages by an indexing factor, it is less likely that earnings at age 65 will be high enough to be included in the benefit computation. If not, $b$ equals zero, and $t$ increases by the value of $b$ reported in the table. ${ }^{5}$ 
The figures also represent average values for $m$ and $b$. Both of these figures can vary greatly across individuals. Given the progressive nature of both the personal income tax schedule and the Social Security benefit formula, individuals with high personal tax rates $m$ will also tend to have low values for $b$, accentuating the variation in $t$ across individuals.

\section{Implications of the Resulting Tax Rates}

What do the average figures tell us about labor supply incentives? While the numbers basically speak for themselves, several implications ought to be noted explicitly:

1) The Social Security Program, in most cases, provides a net subsidy to labor supply throughout the bulk of a person's working life. That is, until age 65 most workers face a net tax rate $t$ which is smaller than their personal tax rate $m$. In fact, for the cohort aged 65 in 1975, labor supply of men with wives receiving spouse's benefits was subsidized on net, in spite of the personal income tax. Even among the cohort aged 65 in 1985 , such couples would face basically no net tax at all throughout the bulk of their lives - the personal income tax is just offset by the Social Security subsidy.

2) The subsidy rate from Social Security drops dramatically between 1975 and 1985 , mainly as a result of the 1977 amendments to the Social Security act. These amendments changed the benefit formula, causing $b$ to fall. While the amendments also increased the size of $a$, this change proved to be less important.

3) For the cohort turning 65 in 2005 , the subsidy from Social Security will effectively have disappeared for those receiving both worker's and spouse's benefits, and turned into a net tax for those receiving just worker's benefits. They pay this net tax rate from Social Security throughout the bulk of their working lives, even while their older contemporaries at any date are likely to face a net subsidy.

4) In all cases, those receiving just worker's benefits fare much worse than those receiving both worker's and spouse's benefits. Female workers fare slightly better than male 
workers. Female spouses, however, normally face very high net tax rates.

5) In all cases, workers face a net tax at age 65 (when $b$ and $e$ are both nonzero). For married men, this tax rate was quite small prior to 1977 , but has risen substantially since then. For single workers, the tax rate was and continues to be extremely high.

6) The individual's net tax rate varies dramatically between years in which earnings do and do not enter the Social Security benefit formula. When a year's earnings do not enter the benefit formula, $b$ would equal zero, and $t$ would increase by the value of $b$ shown in the Table. For example, the net tax rate of a 65 year old in 1975 would be .010 on average if his earnings are high enough to enter the benefit formula, but would increase to $.010+.588=.598$ otherwise. This sharp variation encourages people to concentrate their work effort into those years which do not enter the benefit formula.

7) Since the 1977 amendments, the law has provided an incentive to postpone registration for Social Security benefits until age 65 . That is, for the later two cohorts, the gain from increased future benefits $(a)$ outweighs the loss in current benefits $(e)$. Prior to the amendments, there was very little effect from postponed registration. ${ }^{6}$

8) The earnings test, even with the actuarial adjustment, results in both large and variable net tax rates among individuals already qualified to receive benefits. The resulting net tax rates strongly encourage working hard between ages 62 and 64 rather than working after 65 . Were both the earnings test and the actuarial adjustment eliminated, the net tax rates would change as shown in Table 2 . Such a statutory change leads to both lower tax rates and smoother patterns of tax rates across different ages. 
TABLE 1

\section{Calculation of Net Marginal Tax Rates}

\begin{tabular}{|c|c|c|c|c|c|c|c|c|c|c|c|c|c|c|}
\hline \multirow[b]{2}{*}{ Age } & \multirow[b]{2}{*}{$m$} & \multirow[b]{2}{*}{$p$} & \multirow[b]{2}{*}{$e$} & \multicolumn{3}{|c|}{$\begin{array}{l}\text { Male Worker } \\
\text { with Spouse }\end{array}$} & \multicolumn{3}{|c|}{ Male Worker } & \multicolumn{3}{|c|}{ Female Worker } & \multicolumn{2}{|c|}{$\begin{array}{l}\text { Female } \\
\text { Spouse }\end{array}$} \\
\hline & & & & $a$ & $b$ & $t$ & $a$ & $\boldsymbol{b}$ & $t$ & $a$ & $b$ & $t$ & $a$ & $t$ \\
\hline & & & & \multicolumn{11}{|c|}{ Cohort Aged 65 in 1975} \\
\hline 65 & .135 & .059 & .5 & .146 & .588 & .010 & .044 & .303 & .397 & .054 & .388 & .302 & .0 & .744 \\
\hline 62 & .163 & .052 & .5 & .496 & .535 & -.272 & .398 & .290 & .071 & .484 & .357 & -.082 & .645 & .114 \\
\hline 55 & .188 & .037 & .0 & .0 & .418 & -.164 & .0 & .215 & .039 & .0 & .275 & -.021 & .0 & .254 \\
\hline \multirow[t]{2}{*}{45} & .213 & .02 & .0 & .0 & .379 & -.130 & .0 & .195 & .054 & .0 & .249 & .000 & .0 & .249 \\
\hline & & & & \multicolumn{11}{|c|}{ Cohort Aged 65 in 1985} \\
\hline 65 & .117 & .071 & .5 & .366 & .294 & .090 & .182 & .153 & .415 & .237 & .196 & .317 & .0 & .750 \\
\hline 62 & .139 & .067 & .5 & .768 & .262 & -.266 & .569 & .137 & .058 & .736 & .163 & -.135 & .981 & -.217 \\
\hline 55 & .195 & .059 & .0 & .0 & .294 & .007 & .0 & .153 & .148 & .0 & .196 & .105 & .0 & .301 \\
\hline \multirow[t]{2}{*}{45} & .188 & .036 & .0 & .0 & .294 & -.040 & .0 & .153 & .101 & .0 & .196 & .058 & .0 & .254 \\
\hline & & & & \multicolumn{11}{|c|}{ Cohort Aged 65 in 2005} \\
\hline 68 & .117 & .077 & .5 & .324 & .178 & .259 & $! 159$ & .093 & .509 & .209 & .119 & .433 & .0 & .761 \\
\hline 65 & .139 & .077 & .5 & .691 & .158 & -.068 & .504 & .084 & .193 & .659 & .101 & .021 & .878 & -.097 \\
\hline 55 & .169 & .077 & .0 & .0 & .178 & .131 & .0 & .093 & .216 & .0 & .119 & .190 & .0 & .309 \\
\hline 45 & .169 & .071 & .0 & .0 & .178 & .120 & .0 & .093 & .205 & .0 & .119 & 179 & .0 & .298 \\
\hline
\end{tabular}

Note: For a description of the derivation of these numbers, see the appendix. 
TABLE 2

Effect on the Net Tax Rate of Eliminating the Earnings Test and the Actuarial Adjustment

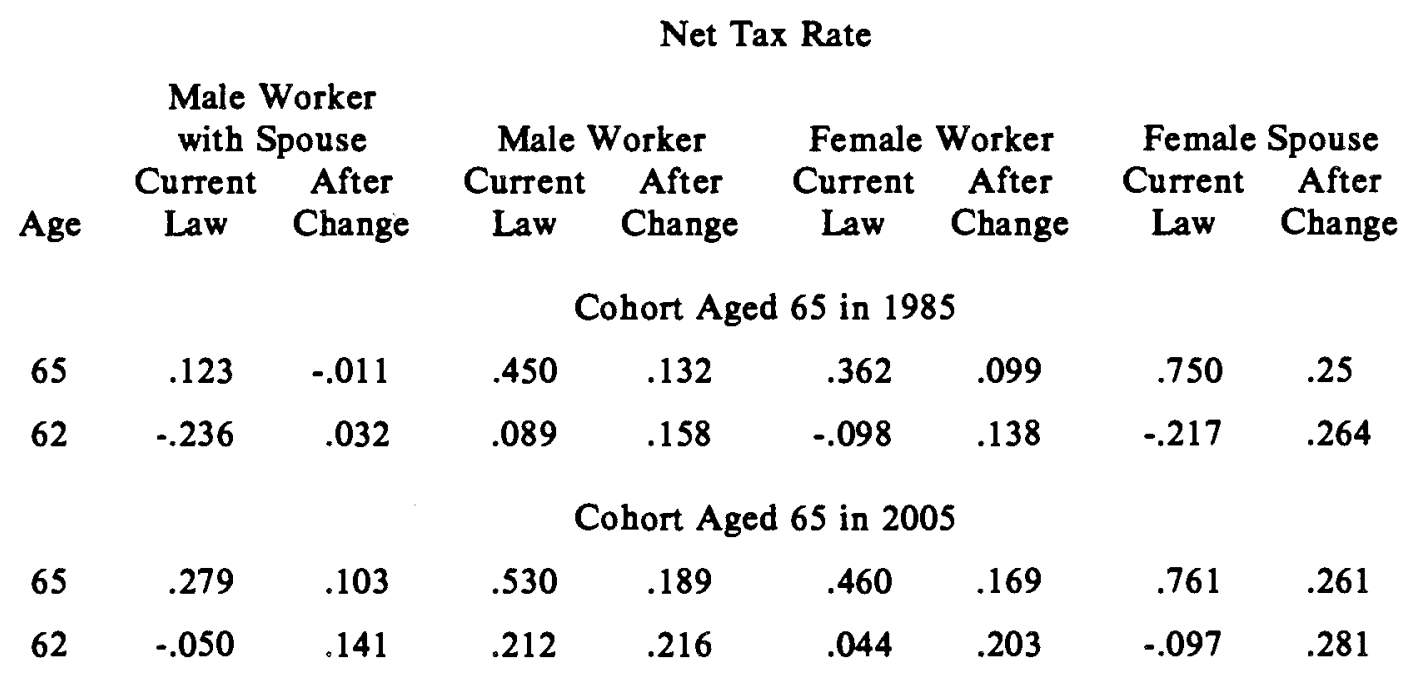




\section{FOOTNOTES}

* Bell Laboratories, Murray Hill, New Jersey. The views expressed in this paper are those of the author, and do not necessarily represent those of Bell Laboratories or the Bell System.

1. It is also too easy to attempt to estimate to what degree individuals change their labor supply in response to any one of these distortions, ignoring the presence of the other distortions.

2. The size of efficiency costs would depend as well on the nature of other distortions, for second best reasons.

3. For earlier attempts, see Burkhauser and Turner $(1978,1981)$.

4. See Blinder, Gordon, and Wise (1980) for further discussion.

5. For the cohort aged 65 in 1975,19 out of the 25 years of earnings between 1951 and 1975 will enter the benefit calculation, in which case $b$ would correspond to the numbers reported in Table 1. During the other six years, $b$ would equal zero. For the cohort aged 65 in 1985,26 out of 35 years of earnings between 1951 and 1985 will enter the benefit calculation, while for the youngest cohort, 38 out of the 44 years of earnings between 1962 and 2005 will enter.

6. While there is a net loss from delaying registration until 63 , there is a slightly larger net gain for postponing registration from 63 to 65 .

7. By law, $I_{t}$ equals 1.0 for ages $t$ over 60 .

8. The intention here is to measure the average $b$ for those whose earnings that year are included in the benefit formula. A slightly larger percent would have had that year's earnings included in the benefit formula, however, than would have had a positive value of $b$ since $b$ would equal zero in addition for those receiving benefits based on the minimum PIA or the special minimum PIA. The reported average value of $b$, as a result, is slightly 
overestimated.

9. For the cohort reaching 65 in $1975, T$ equaled the year they turned 65 (1975) minus 1956. The shift to using age 62 rather than age 65 when computing $T$ was phased in starting the next year.

10. We calculated that for a representative man, $B$ drops by $9.8 \%$ for a worker and spouse, and $11.3 \%$ for a worker only.

11. During the $1952-1980$ period, the ratio was approximately equal to $(1.005)^{65-t}$, assuming a $14 \%$ personal tax rate. Given the decline in productivity growth in recent years, we lowered the ratio slightly, though data for 1981-2 would argue for a much larger drop.

12. These figures for $b$ would be too large ex ante, since $b$ is large due in part to inflation unexpected ten or twenty years earlier. 


\section{APPENDIX \\ Derivation of Tax Rates}

The tax rates reported in Table 1 were calculated using the following procedures:

$e$ and p: These figures reflect the statutory rates prevailing, or specified in the law to prevail, at each date.

$m$ : These figures for the average marginal personal tax rate are rather crude. The basic source of data was a random sample of tax returns from 1972, compiled by the Treasury (the "Tax Sim" file), on which the age of the filer was reported. Daniel Feenberg kindly calculated the average marginal tax rate by age group in this sample.

In order to estimate the average marginal tax rate at each age in years other than 1972, we assumed that the average marginal tax rate at each age was proportional to the overall average tax rate. This average tax rate (tax revenues/taxable income) is reported yearly in the Statistics of Income. We assumed in addition that the latest reported average tax rate would remain unchanged through 2005.

a: The figures for 1975 for the size of the actuarial adjustment for men (or the delayed retirement credit) were taken from Blinder, Gordon, and Wise (1981). The figures for 1985 for men come from Blinder, Gordon, and Wise (1980). The figures for 2005 for men were calculated by the same procedure used for the 1985 figures, but incorporate the assumed postponement in the full and reduced benefit eligibility ages by three years. The figures for women, in all cases were calculated by the same procedures but incorporate female life expectancies, and statutory differences with regard to spouse benefits.

$b$ : The basic source for the various values of $b$ are the calculations reported in Blinder, Gordon and Wise (1980). Their figures are the average of the values of $b$ at age 65 within a large random sample of men reaching age 65 in 1975, calculated under the 1975 law and as they 
would have been after the 1977 amendments.

In describing how the reported figures were derived from these figures, it is worth describing in some detail how $b$ would be calculated after the 1977 amendments. In calculating the size of benefits, first the average indexed monthly earnings (AIME) must be calculated. The AIME equals the average of the $T$ years of highest indexed yearly earnings between 1951 and the current year, where $T$ equals the year in which the individual turns 62 minus 1956 (with a maximum value of 35 ). Indexed earnings at age $t$ equal actual earnings (which are subject to the payroll tax) in year $t$ times the ratio of national average earnings in the year the individual is aged 60 divided by national average earnings in the year the individual is age $t$. Denote this ratio by $I_{t} .^{7}$ Then when the individual earns an extra dollar at age $t$, his AIME increases by $\frac{I_{t}}{12 T}$. (The 12 converts yearly earnings to monthly earnings.)

The next step in computing benefits is to compute the Primary Insurance Amount (PIA), given the value of the AIME. For most individuals under the current law, the slope $\frac{\partial P I A}{\partial A I M E}$ equals .32 . The increase in monthly benefits, assuming registration at age 65 , then equals $\frac{I_{t}}{12 T} \cdot \beta \frac{\partial \mathrm{PIA}}{\partial \mathrm{AIME}}$, where $\beta$ depends on family composition, and equals 1.0 for a retired worker and 1.5 for a worker whose wife receives spouse's benefits. Let $B$ equal the actuarial present value at age 65 of this increase in benefits. (In calculating $B$, we used a $1 \%$ discount rate.) The value of this increase as of age $t$ is then $\frac{B}{(1+r)^{65-1}}$, where $r$ is the after personal tax nominal interest rate.

Note that this procedure omits any effect of current earnings on possible future disability benefits, capturing only the increase in retirement benefits. The resulting estimates of $b$, as reported in Table 1, are slightly too small as a result, particularly at younger ages.

Blinder, Gordon, and Wise (1980) calculated the value of $b$ resulting from earnings of 65 year old men in 1975. Within a random sample of white men, they found an average value for 
$b$ of .543 for married men, whose wives were assumed to receive spouse's benefits, and .256 for the single men. In calculating these figures, however, individuals were included for whom $b$ equaled zero. Among those for whom $b$ was positive, $b$ averaged .588 for married men and .303 for single men. ${ }^{8}$

Had the 1977 amendments applied in 1975, Blinder, Gordon, and Wise (1980) calculated that for 65 year olds the average value of $b$, among those for whom $b$ was positive, would have been .422 for married men and .210 for single men. The reported figures for 65 year old men in 1985 differ because in $1985 T$ equals 26 rather than $19 .{ }^{9}$ The figures for 65 year olds in 2005 differ first in that $T$ now equals 38 (rather than 35 due to the assumed postponement in the retirement age by three years). In addition, $B$ would be lower as a result of the postponement of the start of benefits until age $68 .^{10}$

We had available no equivalent data on the value of $b$ for 65 year old women, so assumed in each case that, except for differences in life expectancy, the value for women would equal that for men. While women would normally have lower earnings, so a higher $b$ due to the progressive PIA formula, those women with a PIA sufficiently high to receive worker's benefits rather than spouse's benefits may not differ that dramatically from men in their value of $b$ (life expectancy aside).

In calculating the values for $b$ at ages 55 and 45 , we assumed that the individual expected to start receiving benefits at age 65 . Then for the cohort aged 65 in 1985 or in 2005 , when the 1977 amendments apply, the value of $b$ at age $t$ equals the value of $b$ at age 65 times $\frac{I_{t}}{(1+r)^{65-t}}$. We set this ratio equal to 1.0 in the calculations. ${ }^{11}$ For the cohort aged 65 in 1975 , prior to the 1977 amendments, the value of $b$ at age $t$ equals the value of $b$ at age 65 discounted at a nominal after tax interest rate. In particular, we used the ten or twenty year government bond rate and the average value of $m$ prevailing in that year. ${ }^{12}$

In calculating $b$ for age 62 , we assumed that the individual started receiving benefits at age 62 rather than age 65 . This, in practice, reduces slightly the present value of benefits, and the 
value of $b$. We calculated the degree of reduction for a representative individual (one with a three year younger spouse, if any, and no other dependents). 


\section{REFERENCES}

Blinder, Alan S., Gordon, Roger H., and Donald E. Wise, "Reconsidering the Work Disincentive Effects of Social Security," National Tax Journal, Dec. 1980, pp. 431-442. , "Rhetoric and Reality in Social Security Analysis - A Rejoinder," National Tax Journal, Dec. 1981, pp. 473-478.

Burkhauser, Richard V., and John A. Turner, "A Time-Series Analysis on Social Security and its Effect on the Market Work of Men at Younger Ages," Journal of Political Economy, August 1978.

"Is the Social Security Tax a Tax," Vanderbilt University working paper, June 1981. 